\title{
Roles of Matrix Metalloproteinases in Tumor Metastasis and Angiogenesis
}

\author{
Sang-Oh Yoon, Soo-Jin Park, Chang-Hyun Yun and An-Sik Chung* \\ Department of Biological Sciences, Korea Advanced Institute of Science and Technology, Daejeon 305-701, Korea
}

\section{Received 5 November 2002}

\begin{abstract}
Matrix metalloproteinases (MMPs), zinc dependent proteolytic enzymes, cleave extracellular matrix (ECM: collagen, laminin, firbronectin, etc) as well as non-matrix substrates (growth factors, cell surface receptors, etc). The deregulation of MMPs is involved in many diseases, such as tumor metastasis, rheumatoid arthritis, and periodontal disease. Metastasis is the major cause of death among cancer patients. In this review, we will focus on the roles of MMPs in tumor metastasis. The process of metastasis involves a cascade of linked, sequential steps that involve multiple host-tumor interactions. Specifically, MMPs are involved in many steps of tumor metastasis. These include tumor invasion, migration, host immune escape, extravasation, angiogenesis, and tumor growth. Therefore, without MMPs, the tumor cell cannot perform successful metastasis. The activities of MMPs are tightly regulated at the gene transcription levels, zymogen activation by proteolysis, and inhibition of active forms by endogenous inhibitors, tissue inhibitor of metalloproteinase (TIMP), and RECK. The detailed regulations of MMPs are described in this review.
\end{abstract}

Keywords: Angiogenesis, Immune escape, Matrix metalloproteinases, Metastasis, Tumor growth

\section{Introduction}

Extracellular proteinases are required for numerous developmental and disease-related processes. The ability to degrade extracellular proteins is essential for any individual cell to interact properly with its immediate surroundings, and for multicellular organisms to develop and function normally. Matrix metalloproteinase (MMP), zinc-dependent proteinases, is one of the potent extracellular matrixes that degrade enzymes. The MMP family currently consists of about 24

*To whom correspondence should be addressed.

Tel: 82-42-869-2625; Fax: 82-42-869-2610

E-mail: aschung@mail.kaist.ac.kr members that are characterized in humans, rodents, and amphibians. Initially, MMPs were classified according to their modular domain structure and ECM specificity (Egeblad and Werb, 2002) (Fig. 1). In addition to their ECM substrates, MMPs also cleave cell surface molecules together with pericellular non-matrix proteins, thereby regulating cell behavior in several ways (McCawley and Matrisian, 2001; Sternlicht and Werb, 2001; Egeblad and Werb, 2002). These substrates include an array of other proteinase, proteinase inhibitors, clotting factors, chemotactic molecules, latent growth factors, growth factor binding proteins, cell surface receptors, and cell-cell and cell-matrix adhesion molecules (Table 1). Therefore, MMPs influence diverse physiologic and pathologic processes. In normal physiology, MMPs are involved in embryonic development, wound repair, ovulation, bone remodeling, macrophage function, and neutrophil function. MMPs also have important functions in pathologic conditions that are characterized by the excessive degradation of ECM, such as tumor metastasis, rheumatoid arthritis, periodontal disease, osteoarthritis, gastric ulcer, and arteriosclerosis (Westermarck and Kahari., 1999). We focus here on the roles of MMPs in tumor cell metastasis.

\section{Tumor Cell Metastasis and MMPs}

Malignant disease is one of the most common causes of death. Most cancer patients do not die from local complications of their primary tumor growth, but rather from the development and spread of the tumor. Therefore, metastasis is a major cause of death among cancer patients. The development of metastasis consists of a complex series of linked, sequential steps, which tumor cells have to accomplish. They are as follows: (1) Disconnection of intercellular adhesions and separation of single cells from solid tumor tissue. (2) Escape from anoikis. (3) Proteolysis of extracellular matrix. (4) Locomotion of tumor cells in the extracellular matrix. (5) Invasion of lymph-and blood vessels. (6) Immunologic escape in the circulation. (7) Adhesion to endothelial cells. (8) Extravasation from lymph-and blood vessels. (9) Proliferation and induction of angiogenesis (Bohle and Kalthoff, 1999; 


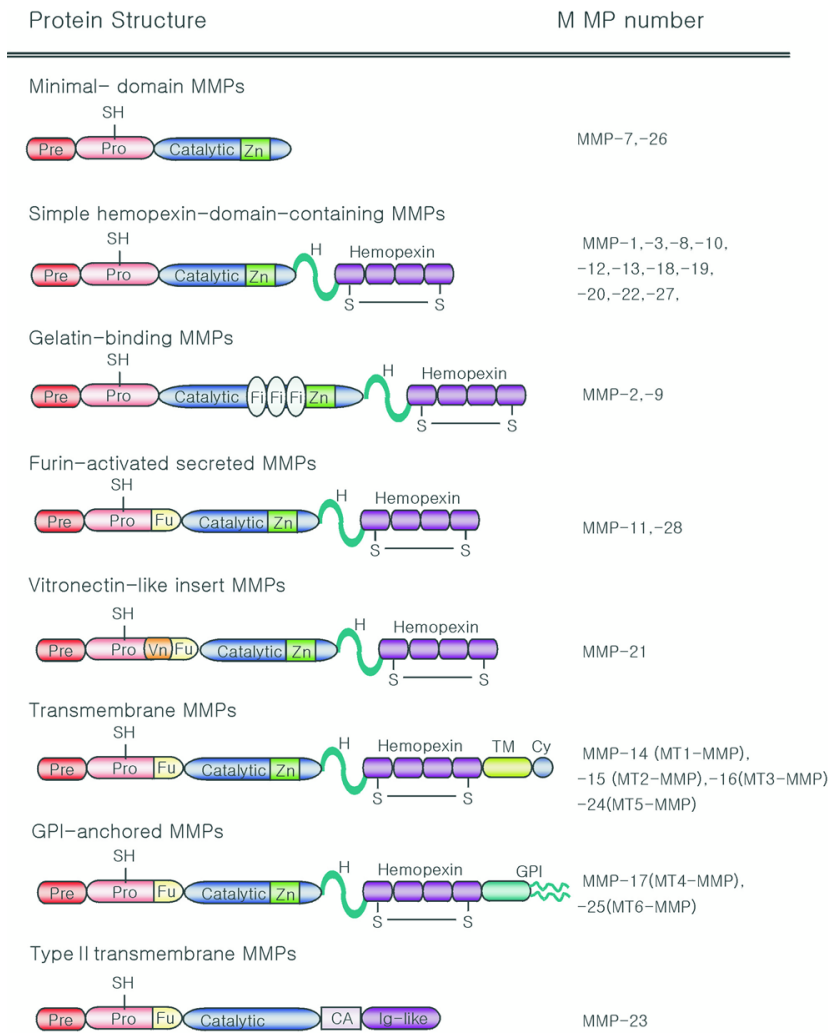

Fig. 1. Protein structures of MMPs. MMPs can be divided by their domain structures. Pre, signal sequence; Pro, propeptide; $\mathrm{H}$, hinge region; Hemopexin, hemopexin-like domain; $\mathrm{Fu}$, furinsusceptible site; TM, transmembrane domain; $\mathrm{Cy}$, cytoplasmic domain; GPI, glycophosphatidyl inositol-anchoring domain; SA, signal anchor domain; CA, cysteine array domain; Ig-like, immunoglobulin-like domain.

Nash et al., 2002) (Fig. 2).

MMPs are the main group of proteolytic enzymes that are involved in the tumor invasion, metastasis, and angiogenesis in cancer (Westermarck and Kahari, 1999; Chang and Werb, 2001). Among the previously reported human MMPs, MMP2 (gelatinase $\mathrm{A} / \mathrm{Mr}$ 72,000 type IV collagenase) and MMP-9 (gelatinase B/ Mr 92,000 type IV collagenase) are abundantly expressed in various malignant tumors (Johnsen et al., 1998). They are considered key enzymes for tumor invasion and metastasis (Liabakk et al., 1996). Other MMPs are also involved in these processes. MMPs function in many steps of metastasis, as will be described later.

\section{Tumor Cell Invasion, Migration and MMPs}

Because of their ECM-degrading activity and the correlation between high levels of their activity and increased tumor metastasis, MMPs were initially thought to facilitate tumor cell metastasis by destroying the basement membrane and other components of ECM. High expression levels of certain
MMPs are related to the tumor invasion capacity in vivo. This has been shown in laryngeal carcinoma with MMP-13 (Cazorla et al., 1998), in esophageal carcinoma with high MMP-7, MMP-9 and MT1-MMP expression levels (Ohashi et al., 2000), and in oral SCCs with high MMP-2, MMP-9, MMP-1, MMP-3, and MT1-MMP expressions (Kurahara et al.,1999). The invasive behavior of gastric carcinoma is associated with the MT1-MMP expression (Bando et al., 1998) and bladder carcinoma with both the MMP-2 and the MT1-MMP expressions (Kanayama et al., 1998). In papillary thyroid carcinoma, the high MMP-2 and MMP-9 expression levels correlate with invasion capacity and lymph node metastasis.

Throughout cancer progression, the microecology of the local host tissue is a consistently active participant in the evolving tumor. Invasion occurs at the tumor-host interface, where the tumor and stromal cells exchange enzymes and cytokines that modulate the local ECM and stimulate cell migration. For tumor invasion and migration, the tumor cells and host coordinately regulate matrix degradation, cell-cell attachments, and cell-matrix attachment. Similar mechanisms are shared by physiological and tumorigenic invasion. In either case, the rate-limiting step is the breakdown of connective tissue barriers, ECM, that comprise collagens, laminins, fibronectin, vitronectin, and heparan sulfate proteoglycans, which require the action of MMPs. The difference between them is that the physiological invasion is regulated, whereas the tumorigenic invasion appears to be perpetual. Initially, it was thought that ECM blocked tumor metastasis not only in the sense of being a physical barrier, but also because it forms a self-protective, apoptosis-resistant microenvironment. However, there is increasing evidence to suggest a supportive role for ECM components in metastasis. A recent study, based on the wholegenomic analysis of metastasis, revealed that the enhanced expression of several genes that are normally involved in the ECM assembly (such as the fibronectin gene) correlated with the progression to a metastatic phenotype (Clark et al., 2000). Degraded matrix increased the metastatic potential: the MMP2-dependent cleavage of laminin-5 induced keratinocyte migration (Giannelli et al., 1997), and the MT1-MMP cleavage of laminin-5 allowed the migration of a variety of cell types (Koshikawa et al., 2000).

Besides degrading ECM by MMPs, tumor cell invasion and migration rely on the adhesion receptor-dependent attachment to, and release from, the matrix and other cells. MMP activity may also directly modulate the attachment and migration by cleaving cell-cell or cell-matrix receptors (Murphy and Gavrilovic, 1999). For example, $\beta 4$ integrin is cleaved by MMP-7 (von Bredow et al., 1997), and the MMP-mediated proteolytic removal of E-cadherin has been demonstrated (Lochter et al., 1997; Noe et al., 2001). The MMP-3 and 7 cleavage of E-cadherin not only disrupts adhesion junctions, but also releases a dominant-negative ectodomain fragment that stimulates cellular migration and invasion through a collagen gel (Noe et al., 2001). 
Table 1. MMP substrates

\begin{tabular}{|c|c|c|c|}
\hline \multirow{2}{*}{ MMP } & \multirow{2}{*}{ Matrix } & \multicolumn{2}{|c|}{ Non matrix } \\
\hline & & Substrate & Resultant \\
\hline \multirow[t]{6}{*}{ MMP-1 } & Collagen I/II/III/VI/X & Perlecan & Bioavailable FGF \\
\hline & Gelatin & IGFBP-2,3 & Bioavailable IGF \\
\hline & Entactin & $\alpha 1$-antichymotrypsin & Inactive serpin \\
\hline & Aggrecan & $\alpha 1$-proteinase inhibitor & Inactive serpin \\
\hline & Tenascin & Pro-MMP1,2 & MMP-1,2 \\
\hline & & Pro-TNF $\alpha$ & Bioavailable TNF $\alpha$ \\
\hline \multirow[t]{8}{*}{ MMP-2 } & Gelatin & Decorin & Bioavailable TGF $\beta$ \\
\hline & Elastin & Pro-TGF- $\beta 2$ & TGF- $\beta 2$ \\
\hline & Fibronectin & Pro- IL1- $\beta$ & Active IL1- $\beta$ \\
\hline & Collagen I/IV/V/VI/X/XI & MCP-3 & Inactive chemoattractant \\
\hline & Laminin & IGFBP-3/5 & Bioavailable IGF \\
\hline & Aggrecan & Pro-TNF $\alpha$ & $\mathrm{TNF} \alpha$ \\
\hline & Vitronectin & FGF-R1 & Bioactive FGF-R1 ectodomain \\
\hline & & Pro-MMP-1,2,13 & MMP-1,2,13 \\
\hline \multirow[t]{11}{*}{ MMP-3 } & Proteoglycans & Perlecan & Bioavailable FGF \\
\hline & Laminin & Decorin & Bioavailable TGF \\
\hline & Fibronectin & Pro-HB-EGF & HB-EGF \\
\hline & Gelatin & Pro- IL1- $\beta$ & IL1- $\beta$ \\
\hline & Collagen III/IV/V/VI/IX/X/XI & Plasminogen & Angiostatin \\
\hline & Fibrin/fibrinogen & E-cadherin & Bioactive E-cadherin ectodomain \\
\hline & Entactin & IGFBP-3 & Bioavailable IGF \\
\hline & Tenascin & $\alpha 1$-antichymotrypsin & Inactive serpin \\
\hline & Vitronectin & $\alpha 1$-proteinase inhibitor & Inactive serpin \\
\hline & & Pro-MMP-1,3,7,8,9,13 & MMP-1,3,7,8,9,13 \\
\hline & & Pro-TNF $\alpha$ & Bioavailable TNF $\alpha$ \\
\hline \multirow[t]{9}{*}{ MMP-7 } & Proteoglycans & Pro-a-defensin & $\alpha$-Defensin \\
\hline & Laminin & Decorin & Bioavailable TGF $\beta$ \\
\hline & Fibronectin & Cell surface bound Fas-L & Active soluble Fas-L \\
\hline & Gelatin & & Inactive soluble Fas-L \\
\hline & Collagen III/IV/V/IX/X/XI & $\beta 4$ integrin & Release of $\beta 4$ integrin \\
\hline & Fibrin/fibrinogen & E-cadherin & Bioactive E-cadherin ectodomain \\
\hline & Entactin & Plasminogen & Angiostatin \\
\hline & Tenascin & Pro-TNF $\alpha$ & Bioavailable TNF $\alpha$ \\
\hline & Vitronectin & Pro-MMP2,7 & MMP-2,7 \\
\hline \multirow[t]{7}{*}{ MMP-9 } & Gelatin & Unknown & Bioavailable VEGF \\
\hline & Elastin & Pro-TGF- $\beta 2$ & TGF- $\beta 2$ \\
\hline & Fibronectin & Pro- IL1- $\beta$ & Active IL1- $\beta$ \\
\hline & Collagen I/IV/V/VI/X/XI & Cell surface bound IL- $2 \mathrm{R} \alpha$ & Release of IL-2R $\alpha$ \\
\hline & Laminin & Plasminogen & Angiostatin \\
\hline & Aggrecan & $\alpha 1$-proteinase inhibitor & Inactive serpin \\
\hline & Vitronectin & Pro-TNF $\alpha$ & $\mathrm{TNF} \alpha$ \\
\hline \multirow[t]{2}{*}{ MMP-11 } & Laminin, Fibronectin & $\alpha 1$-proteinase inhibitor & Inactive serpin \\
\hline & Aggrecan & IGFBP-1 & Bioavailable IGF \\
\hline \multirow[t]{5}{*}{ MMP-13 } & Collagen I/II/III/VI/X & $\alpha 1$-antichymotrypsin & Inactive serpin \\
\hline & Gelatin & Pro-MMP-9,13 & MMP-9,13 \\
\hline & Entactin & & \\
\hline & Aggrecan & & \\
\hline & Tenascin & & \\
\hline
\end{tabular}

What is the source of MMPs? In most malignant tumors, stromal fibroblasts are the primary source of MMPs. The infiltration of inflammatory cells is a prominent feature of many tumors. They also produce MMPs to the peritumoral environment. Inflammatory cells also produce cytokines, which enhance the expression of MMPs by tumor and stromal 


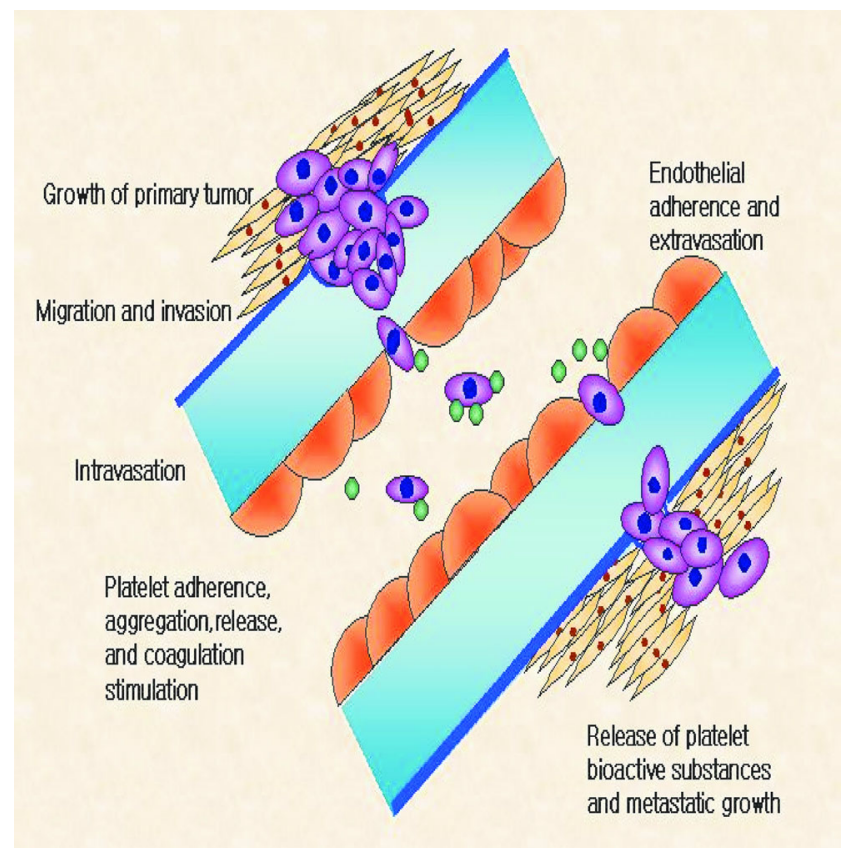

Fig. 2. A schematic figure of tumor cell metastasis. Tumor cell metastasis is the major cause of death of cancer patients. Successful metastasis requires sequential steps, such as tumor cell invasion, migration, host immune escape, extravasation, angiogenesis, and tumor growth.

cells. Tumor cells produce factors, such as chemokines, cytokines, and the extracellular matrix metalloprotease inducer (EMMPRIN), which in turn activates the tumor-cell invasion (Biswas et al., 1995; Westermarck et al., 2000; Sun and Hemler, 2001) through the up-regulation of MMPs. In turn, MMPs generate a chemotactic signal in several systems. MMP-9 is required for the release of vascular endothelial growth factor (VEGF) during long bone development. Then VEGF acts as a chemoattractant for osteoblast recruitment (Engsig et al., 2000). In addition, MMP-3 releases an unidentified macrophage chemoattractant in a co-culture model of herniated disc resorption (Haro et al., 2000). MMPs also play a role in dampening the chemotactic response. For example, the monocyte chemoattractant protein (MCP)-3 is cleaved and inactivated by MMP-2, attenuating chemotaxis and the inflammatory response (McQuibban et al., 2000).

\section{Roles of MMPs in Immunologic Escape in the Circulation and Extravasation}

Once the tumor cell has entered the circulation, it is in danger of being recognized by immunocompetent cells, which are responsible for the elimination of circulating tumor cells. In order to be successful in the establishment of metastases, a tumor cell has to adopt certain mechanisms of immune escape. MMPs are involved in immune escape by the stimulation of cancer cell-platelet interactions and inhibition of functions, as well as the proliferation of immune responsible cells, such as the T cell and natural killer cells.

It is well documented that platelets play an integral role in the hematogenous spread of cancerous cells during the metastatic cascade (Nash et al., 2002). Human tumor cells are frequently found in association with thrombi. The ability of malignant tumor cells to aggregate platelets confers a number of advantages to the successful metastasis of cancer cells (Nieswandt et al., 1999). When covered with a coat of platelets, a tumor cell acquires the ability to evade the bodys immune system (Philippe et al., 1993). Another survival advantage for the tumor cell is the tendency for the large tumor-platelet aggregate to embolize the microvasculature at a new extravasation site (Malik, 1983). Furthermore, platelets facilitate the extravasation of tumor cells (Mehta, 1984). The success of circulating metastases relies on extravasation, which means that the tumor cell must slow down to attach to the vascular endothelium. However, in blood that flows at a normal rate, shear forces oppose cell attachment. The cells must, therefore, be equipped with adhesive mechanisms (Konstantopoulos and McIntire, 1997). The platelet enables tumor cell extravasation that facilitates the adhesion of tumor cells to the vascular endothelium. MMP is found to stimulate platelet aggregation; therefore, the tumor cell metastatic potential increases (Sawicki et al., 1997).

MMPs are also involved in the $\mathrm{T}$ cell function. MMP mediates the cleavage of IL- $2 \mathrm{R} \alpha$ and down-regulates the proliferative capability of the cancer-encountered $\mathrm{T}$ cells (Sheu et al., 2001). Because IL-2R $\alpha$ plays a pivotal role in the development and propagation of functional $\mathrm{T}$ cells, its depressed expression results in the poor function of tumorreactive cytotoxic lymphocytes. MMPs also activate TGF- $\beta$ (Yu and Stamenkovic, 2000), an important inhibitor of the Tlymphocyte response against tumors (Gorelik and Flavell, 2001). In addition to the T lymphocyte, MMPs also affect natural killer (NK) cells. The resistance of breast cancer cells to NK cell-mediated cytotoxicity is induced by MMP-9 dependent ICAM-1 shedding. ICAM-1 provides a cell surface-docking mechanism for proMMP-9, which, upon activation, proteolytically cleaves the extracellular domain of ICAM-1. This then leads to its release from the cell surface (Fiore et al., 2002). MMP-11 is also involved in the tumor cell evasion of immune surveillance. A cleavage product of the $\alpha 1$-proteinase-inhibitor, generated by MMP-11 (Kataoka et al., 1999), decreases the sensitivity of tumor cells to NK cells. In addition, an increased number of neutrophils and macrophages infiltrate tumors in the Mmpll-null mice when compared to the wild-type mice. This indicates that MMP-11 inhibits a chemoattractant for these cells (Boulay et al., 2001).

\section{Angiogenesis and MMPs}

The process of angiogenesis is governed by an integrated 
signaling circuitry, and its modulation is dependent upon soluble angiogenic factors, cytokines, and insoluble ECM components that surround the participating vessels (Cho et al., 2002). Angiogenesis is necessary for persistent tumor growth, because the sprouting capillaries are conduits for gas exchange and nutrient supply (Carmeliet and Jain, 2000). Without vascular growth, the tumor mass is restricted to within a tissue-diffusion distance of approximately $0.2 \mathrm{~mm}$. Tumor vessels are recruited by sprouting or intussusception from pre-existing vessels, in which interstitial tissue columns are inserted into the lumen of pre-existing vessels and partition the vessel lumen. MMPs are essential regulators during various phases of the angiogenic process-from the deposition and breakdown of the basement membrane of vascular structures (depending on the effects of MMPs on the matrix substrates) to the endothelial cell proliferation and migration (depending on the mobilization of the latent growth factors and receptor shedding) (Pepper, 2001). Many in vivo and in vitro experiments identified the involvement of MMPs in tumor vascularization. The head and neck carcinomas that are negative for MMP-9 have smaller microvessel density than positive tumors (Riedel et al., 2000). The role of MMPs in angiogenesis has also been implicated in studies with knockout mice. Disturbed angiogenesis has been noted in mice that lack MMP-2, -9 and MT1-MMP (Hiraoka et al., 1998; Itoh et al., 1998, 1999; Bergers et al., 2000; Zhou et al., 2000). The inhibition of angiogenesis was also detected in in vivo studies by the treatment of tumor-bearing animals with MMP inhibitors. The inhibition of angiogenesis in vivo has been shown at least with MMP inhibitors prinomastat, BAY 12-9566, batimastat, BMS-275291, neovastat, and metastat (Ferrante et al., 1999; Gatto et al., 1999; Shalinsky et al., 1999; Silvestre et al., 2001).

Based on recent findings, a model to explain the role of MMPs during angiogenesis in cancer is described (Nguyen et al., 2001). Endothelial cells continually secrete latent MMP-2 under basal conditions in vitro. In vivo, MMP-2 was found to be strongly expressed by some endothelial cell types, including human glioblastomas (Vince et al., 1999). Thrombin, which is present at high levels in angiogenic situations such as cancer (Wojtukiewicz et al., 1993; EvenRam et al., 1998) and rheumatoid arthritis (Morris et al., 1994), interacts with thrombomodulin on the endothelial surface and activates protein $\mathrm{C}$. This rapidly activates latent MMP-2, which causes disruption of the existing capillary bed. The effect of thrombin is likely to be short-lived as it is readily incorporated into fibrin clots, immobilized in the subendothelial basement membrane, or inactivated by agents such as antithrombin III, protein C inhibitor, heparin co-factor II or heparin. Other angiogenic agents (such as hydrogen peroxide and the hepatocyte growth factor) may also contribute to the activation of MMP-2. As endothelial cells migrate during this initial phase of angiogenesis, MMP-9 may participate in the degradation of the basement membrane. It is feasible that MMP-9 is secreted from the storage vesicles within the cell in short bursts in order to locally degrade the basement membrane.

Part of the influence of MMPs and TIMPs on angiogenesis is mediated by their effects on pro-angiogenic molecules (e.g. members of the VEGF and angiopoietin family) and antiangiogenic molecules (e.g., angiostatin). A recent study demonstrated that the switch from vascular quiescence to angiogenesis involved MMP-9, which was up-regulated in angiogenic islets and tumors, releasing VEGF-A from an extracellular reservoir (Bergers et al., 2000). Although VEGF$\mathrm{A}$ is well established as an inducer of angiogenesis, the function of other VEGF isoforms is not as well characterized. VEGF-C is particularly intriguing because it regulates lymphangiogenesis, therefore, it may contribute to metastasis. In addition, its activity is regulated by proteolysis (Joukov et al., 1997). The proteolytic cleavage of VEGF-C dramatically increases its binding to VEGFR-3, and enhances its efficacy for lymphangiogenesis. It also makes it acquire binding for VEGFR-2 and promotes its angiogenic potential. The role of a second group of angiogenic factors in development, the FGFs, remains elusive, even though they are required for maintaining tumor angiogenesis (Compagni et al., 2000). As in the case for VEGF, MMPs might regulate the bioavailability of FGFs. By contrast, another study revealed that mice that are null for integrin $\alpha 1$ (a molecule that is normally an inhibitor of MMP synthesis) display increased plasma levels of angiostatin because of the action of MMP-7 and MMP-9 on plasminogen. This results in reduced tumor vascularization (Pozzi et al., 2000). It is interesting that MMP$3,-7,-9$, and -12 can generate angiostatin from plasminogen, which indicates that their activity in the peritumoral area may inhibit tumor-induced angiogenesis (Dong et al., 1997; Patterson and Sang, 1997; Lijnen et al., 1998). Recent observations also show that endostatin can inhibit the catalytic activities of both MMP-2 and MT1-MMP (Kim et al., 2000). Therefore, during angiogenesis, MMPs can have both a proangiogenic role, by releasing matrix-bound pro-angiogenic factors, and also an anti-angiogenic role, by cleaving the ECM components into anti-angiogenic factors. The balance between the two roles in the development dictates the outcome of the angiogenic switch by MMPs. It is also important to note that the ECM fragments that are cleaved by MMPs can also be pro-angiogenic molecules. For example, the trimeric $\mathrm{NC1}$ domain of collagen XVIII induces endothelial cell migration in angiogenesis (Kuo et al., 2001).

\section{MMPs and Tumor Growth and Progression}

The evidence of tumor growth promotion by MMPs came from studies of MMPs knockout mice and their endogenous tissue inhibitors (TIMPs). Mice that lack MMP-7 show a reduction in intestinal tumorigenesis (Pozzi et al., 2000). MMP-11 knockout mice show reduced tumorigenesis in response to chemical mutagenesis (Masson et al., 1998). 
MMP-9-deficient mice show a reduced formation of melanoma metastases (Itoh et al., 1999). MMP-2-deficient mice show reduced melanoma tumor progression and angiogenesis (Itoh et al., 1998). Transgenic technology revealed the TIMP/MMP action. For example, the antisensemediated reduction of TIMP-1 resulted in a more rapid tumor initiation and progression (Martin et al., 1996), and the TIMP1 overproduction slowed chemical carcinogenesis in the skin (Buck et al., 1999), as well as SV40 large T antigen-induced liver carcinogenesis in transgenic mice (Martin et al., 1996). Therefore, these results suggest that MMPs are important contributors to tumor growth and progression.

How can MMPs promote tumor cell growth? Successful tumor cells are those that induce the release of growthstimulating signals from neighboring cells. The release of the extracellular domains of proteins from the cell surface by a mechanism that involves metalloprotease-directed proteolysis is referred to as ectodomain shedding. In addition to ectodomain shedding, the release from matrix binding also serves as a major mechanism for making growth regulators bioavailable to cells that are not in direct physical contact. MMPs participate in cell-surface proteolysis, leading to the release of a growing list of cell-surface growth regulators. Because MMPs degrade proteins in ECM, their primary function was considered to be the remodeling of ECM. However, MMPs also act on the non-matrix substrates (e. g., chemokines, growth factors, growth factor receptors, adhesion molecules, and apoptotic mediators) that yield the rapid and critical cellular responses that are required for tumor growth and progression. For example, MMP-2 influences the cellsurface receptor-mediated signaling by releasing the active ectodomain of the fibroblast growth factor receptor 1 (FGFR1) (Levi et al., 1996). The coordinated regulation of MMPs and TIMPs, therefore, governs the cleavage and release of many important growth factors and cell-surface receptors.

\section{Regulation of MMPs}

The regulation of the MMP function occurs at multiple levels. The MMP mRNA expression is under tight, cell typedependent control with the expression of individual MMPs that are associated with specific inflammatory, connective tissue, or epithelial cell types. MMP transcripts are generally expressed at low levels, but these levels rise rapidly when tissues undergo remodeling, such as in inflammation, wound healing, and cancer. The MMP genes that are inducible by extracellular stimuli (MMP-1, MMP-3, MMP-7, MMP-9, MMP-10, MMP-12, and MMP-13) harbor an AP-1 (activator protein-1) binding site in the proximal promoter (Westermarck and Kahari, 1999). In contrast, the promoters of the MMP-2, MMP-11, and MT1-MMP genes contain no AP1 elements. Extracellular signals activate the dimeric AP-1 complex, composed of Jun and Fos proteins, which bind to the AP-1 element and activate the transcription. The induction of the expression and activity of AP-1 are mediated by 3 classes of mitogen-activated protein kinases (MAPKs). They are the mitogen-activated extracellular signal-regulated kinase1, 2 (ERK1, 2), stress-activated Jun N-terminal kinases, and p38 MAPK (Westermarck and Kahari, 1999; Cho and Choi, 2002). Another cis-element, the PEA3 (polyomavirus enhancer A-binding protein-3) site, is present in the promoters of MMP-1, MMP-3, and MMP-9, in which it can cooperate with the AP-1 element (Westermarck and Kahari, 1999). In the case of MMP-9, this can also be regulated by NF- $\mathrm{KB}$ (Kim and Chung, 2002). Therefore, the inhibition of NF- $\mathrm{BB}$ downregulates MMP-9. In our experiment, it was shown that selenite inhibits MMP-9, and the tumor invasion may be through the suppression of NF- $\mathrm{KB}$ (Yoon et al., 2002).

MMPs are synthesized as latent enzymes that can be stored in inflammatory cell granules, but are more often secreted and found anchored to the cell surface or tethered to other proteins on the cell surface or within the ECM. The Zymogen forms of MMPs are proteolytically activated in the pericellular space by tissue or plasma proteinases, bacterial proteinases, or other MMPs. MMP-11, -23, -28, and MT-MMPs are activated prior to secretion by the Golgi-associated furin proteases (Pei and Weiss, 1995). In the case of proMMP-2, this enzyme can be activated by several mechanisms that are dependent on stimulators and cell types. For example, we showed that the sustained production of hydrogen peroxide activates proMMP-2 through the receptor tyrosine kinases/PI3-kinase/ NF- $\kappa B$ pathway in HT1080 cells (Yoon et al., 2001). Initially, ProMMP-2 can be activated by the action of highly-expressed MT1-MMP and the adequate expression of TIMP-2 (Sato et al., 1994; Sternlicht and Werb, 2001). In this situation, the balance between MT1-MMP and TIMP-2 is important. At low concentrations, TIMP-2 binds to the catalytic site of some of the activated MT1-MMP molecules that generate receptors for pro-MMP-2, thereby promoting the MMP-2 activation. In this situation, MT1-MMP forms a homophilic complex through the hemopexin-like (PEX) domain that acts as a mechanism to keep MT1-MMP molecules close together in order to facilitate the proMMP-2 activation (Itoh et al., 2001). At high concentrations, TIMP-2 binds and inhibits any active MT1-MMP, therefore, completely preventing the MMP-2 activation. On the other hand, the down-regulation of TIMP-2 by the type IV collagen, without affecting MT1-MMP, can lead to the proMMP-2 activation (Maquoi et al., 2000). In this case, the pro-MMP-2 activation involves neither a transcriptional modulation of the MMP-2, MT1-MMP, or TIMP-2 expression nor any alteration of the MT1-MMP protein synthesis or processing. Finally, the activation of proMMP-2 in fibroblast that is cultured in the type I collagen lattice is induced intracellularly; it is associated with the Golgi-enriched intracellular membranes without the aid of MT1-MMP (Lee et al., 1997).

The proteolytic activity of MMPs is specifically inhibited by tissue inhibitors of metalloproteinases (TIMPs). The TIMP gene family consists of 4 members: TIMP-1, $-2,-3$ and 4 
(Brew et al., 2000). TIMPs inhibit the activity of MMPs by binding to activated MMPs in a 1:1 molar stoichiometry. TIMPs can also inhibit the growth, invasion, and metastasis of malignant tumors (Kahari and Saarialho-Kere, 1999). In addition to TIMPs, the $\alpha 1$-proteinase inhibitor and $\alpha 2$ macroglobulin, the C-terminal fragment of procollagen $\mathrm{C}$ terminal protease enhancer, tissue factor pathway inhibitor 2 , proteolytic fragments of MMP substrates, and the recently characterized RECK (reversion inducing cysteine-rich protein with Kazal motifs) protein, a novel plasma-membraneanchored MMP inhibitor, regulate MMPs activity (Mott et al., 2000; Herman et al., 2001; Oh et al., 2001; Sternlicht and Werb, 2001)

RECK is a $110-\mathrm{kDa}$ glycoprotein that contains a serineprotease inhibitor-like domain, two domains that contains the epidermal growth factor (EGF)-like repeats, and a C-terminal domain the encodes a glycosylphosphatidylinositol (GPI) modification that anchors RECK to the plasma membrane (Takahashi et al., 1998). RECK regulates at least three members of the MMP family-MMP-2, MMP-9, and MT1MMP-by various mechanisms (Takahashi et al., 1998; Oh et al., 2001). Membrane-anchored RECK inhibits the secretion of proMMP-9; whereas, both the membrane-anchored and soluble RECK directly inhibit the MMP-2, -9, and MT1MMP catalytic activity. In addition, RECK inhibits both of the catalytic steps of the proMMP-2 activation. By inhibiting the MT1-MMP activity, RECK inhibits the processing of proMMP-2 to the intermediate species. RECK also inhibits the final processing step of proMMP-2, where the intermediate-processed form is autolytically activated. In the context of tumor development, the overexpression of RECK in HT1080 cells results in the attenuated-tumor formation in nude mice as a consequence of the limited-angiogenic sprouting (Oh et al., 2001). Since the balance between the ECM deposition and degradation is the key for endothelial cell homeostasis, then it is probable that RECK contributes functionally to vasculogenesis and angiogenesis by attenuating the degradation of MMP substrates (Rhee and Coussens, 2002).

\section{Conclusions}

MMPs play a crucial role in every step of tumor metastasis. Originally, it was thought that MMPs increase the metastatic potential through the degradation of the extracellular matrix. Much evidence shows that MMPs also control non-matrix substrates, such as growth factors and cell surface receptors. In turn, the multiple extracellular factors (including cytokines, growth factors, and interactions with adjacent cell and ECM) regulate MMPs expressions and activities. In clinical trials, however, many MMPs inhibitors have not been successful in treating cancer. A greater understanding of MMPs is required for the therapeutic application of MMPs inhibitors for cancer treatment. The following questions need to be addressed:
What MMPs function on what steps of metastasis? What are the real in vivo substrates of MMPs? What are the biological outcomes of their cleavage products?

\section{References}

Bando, E., Yonemura, Y., Endou, Y., Sasaki, T., Taniguchi, K., Fujita, H., Fushida, S., Fujimura, T., Nishimura, G., Miwa, K. and Seiki, M. (1998) Immunohistochemical study of MT-MMP tissue status in gastric carcinoma and correlation with survival analyzed by univariate and multivariate analysis. Oncol. Rep. 5, 1483-1488.

Bergers, G., Brekken, R., McMahon, G., Vu, T. H., Itoh, T., Tamaki, K., Tanzawa, K., Thorpe, P., Itohara, S., Werb, Z. and Hanahan, D. (2000) Matrix metalloproteinase-9 triggers the angiogenic switch during carcinogenesis. Nature Cell Biol. 10, 737-744.

Biswas, C., Zhang, Y., DeCastro, R., Guo, H., Nakamura, T., Kataoka, H. and Nabeshima, K. (1995) The human tumor cellderived collagenase stimulatory factor (renamed EMMPRIN) is a member of the immunoglobulin superfamily. Cancer Res. 55, 434-439.

Bohle, A. S. and Kalthoff, H. (1999) Molecular mechanisms of tumor metastasis and angiogenesis. Langenbecks Arch. Surg. 384, 133-140.

Boulay, A., Masson, R., Chenard, M. P., El Fahime, M., Cassard, L., Bellocq, J. P., Sautes-Fridman, C., Basset, P. and Rio, M. C. (2001) High cancer cell death in syngeneic tumors developed in host mice deficient for the stromelysin-3 matrix metalloproteinase. Cancer Res. 61, 2189-2193.

Brew, K., Dinakarpandian, D. and Nagase, H. (2000) Tissue inhibitors of metalloproteinases: evolution, structure and function. Biochim. Biophys. Acta 1477, 267-283.

Buck, T. B., Yoshiji, H., Harris, S. R., Bunce, O. R. and Thorgeirsson, U. P. (1999) The effects of sustained elevated levels of circulating tissue inhibitor of metalloproteinases- 1 on the development of breast cancer in mice. Ann. N. Y. Acad. Sci. 878, 732-735.

Carmeliet, P. and Jain, R. K. (2000) Angiogenesis in cancer and other diseases. Nature 407, 249-257.

Cazorla, M., Hernandez, L., Nadal, A., Balbin, M., Lopez, J. M., Vizoso, F., Fernandez, P. L., Iwata, K., Cardesa, A., LopezOtin, C. and Campo, E. (1998) Collagenase-3 expression is associated with advanced local invasion in human squamous cell carcinomas of the larynx. J. Pathol. 186, 144-150.

Chang, C. and Werb, Z. (2001) The many faces of metalloproteases: cell growth, invasion, angiogenesis and metastasis. Trends Cell. Biol. 11, S37-S43.

Cho, H., Kim, W. J., Lee, S. W., Kim, Y. M., Choi, E. Y., Park, Y. S., Kwon, Y. G. and Kim, K. W. (2001) Anti-angiogenic activity of mouse N-/C-terminal deleted endostatin. J. Biochem. Mol. Biol. 34, 206-211.

Cho, S. G. and Choi, E. J. (2002) Apoptotic signaling pathways: caspases and stress-activated protein kinases. J. Biochem. Mol. Biol. 35, 24-27.

Clark, E. A., Golub, T. R., Lander, E. S. and Hynes, R. O. (2000) Genomic analysis of metastasis reveals an essential role for RhoC. Nature 406, 532-535.

Compagni, A., Wilgenbus, P., Impagnatiello, M. A., Cotten, M. 
and Christofori, G. (2000) Fibroblast growth factors are required for efficient tumor angiogenesis. Cancer Res. 60, 7163-7169.

Dong, Z., Kumar, R., Yang, X. and Fidler, I. J. (1997) Macrophage-derived metalloelastase is responsible for the generation of angiostatin in Lewis lung carcinoma. Cell 88, 801-810.

Egeblad, M. and Werb, Z. (2002) New functions for the matrix metalloproteinases in cancer progression. Nature Rev. Cancer $\mathbf{2}$, 161-174.

Engsig, M. T., Chen, Q. J., Vu, T. H., Pedersen, A. C., Therkidsen, B., Lund, L. R., Henriksen, K., Lenhard, T., Foged, N. T., Werb, Z. and Delaisse, J. M. (2000) Matrix metalloproteinase 9 and vascular endothelial growth factor are essential for osteoclast recruitment into developing long bones. J. Cell Biol. 151, 879-889.

Even-Ram, S., Uziely, B., Cohen, P., Grisaru-Granovsky, S., Maoz, M., Ginzburg, Y., Reich, R., Vlodavsky, I. and Bar-Shavit, R. (1998) Thrombin receptor overexpression in malignant and physiological invasion processes. Nature Med. 4, 909-914.

Ferrante, K., Winograd, B. and Canetta, R. (1999) Promising new developments in cancer chemotherapy. Cancer Chemother. Pharmacol. 43, Suppl: S61-S68.

Fiore, E., Fusco, C., Romero, P. and Stamenkovic, I. (2002) Matrix metalloproteinase 9 (MMP-9/gelatinase B) proteolytically cleaves ICAM-1 and participates in tumor cell resistance to natural killer cell-mediated cytotoxicity. Oncogene 21, 5213-5223.

Gatto, C., Rieppi, M., Borsotti, P., Innocenti, S., Ceruti, R., Drudis, T., Scanziani, E., Casazza, A. M., Taraboletti, G and Giavazzi, R. (1999) BAY 12-9566, a novel inhibitor of matrix metalloproteinases with antiangiogenic activity. Clin. Cancer Res. 5, 3603-3607.

Giannelli, G., Falk-Marzillier, J., Schiraldi, O., Stetler-Stevenson, W. G. and Quaranta, V. (1997) Induction of cell migration by matrix metalloprotease-2 cleavage of laminin-5. Science 277, 225-228.

Gorelik, L. and Flavell, R. A. (2001) Immune-mediated eradication of tumors through the blockade of transforming growth factor-beta signaling in T cells. Nature Med. 7, 11181122.

Haro, H., Crawford, H. C., Fingleton, B., MacDougall, J. R., Shinomiya, K., Spengler, D. M., Matrisian, L. M. (2000) Matrix metalloproteinase-3-dependent generation of a macrophage chemoattractant in a model of herniated disc resorption. J. Clin. Invest. 105, 133-141.

Herman, M. P., Sukhova, G.. K., Kisiel, W., Foster, D., Kehry, M. R., Libby, P. and Schonbeck, U. (2001) Tissue factor pathway inhibitor-2 is a novel inhibitor of matrix metalloproteinases with implications for atherosclerosis. J. Clin. Invest. 107, 11171126.

Hiraoka, N., Allen, E., Apel, I. J., Gyetko, M. R. and Weiss, S. J. (1998) Matrix metalloproteinases regulate neovascularization by acting as pericellular fibrinolysins. Cell 95, 365-377.

Itoh, Y., Takamura, A., Ito, N., Maru, Y., Sato, H., Suenaga, N., Aoki, T. and Seiki, M. (2001) Homophilic complex formation of MT1-MMP facilitates proMMP-2 activation on the cell surface and promotes tumor cell invasion. EMBO J. 20, 47824793.

Itoh, T., Tanioka, M., Matsuda, H., Nishimoto, H., Yoshioka, T.,
Suzuki, R. and Uehira, M. (1999) Experimental metastasis is suppressed in MMP-9-deficient mice. Clin. Exp. Metastasis 17, 177-181.

Itoh, T., Tanioka, M., Yoshida, H., Yoshioka, T., Nishimoto, H. and Itohara, S. (1998) Reduced angiogenesis and tumor progression in gelatinase A-deficient mice. Cancer Res. 58, 1048-1051.

Johnsen, M., Lund, L. R., Romer, J., Almholt, K. and Dano, K. (1998) Cancer invasion and tissue remodeling: common themes in proteolytic matrix degradation. Curr. Opin. Cell Biol. 10, 667-671.

Joukov, V., Sorsa, T., Kumar, V., Jeltsch, M., Claesson-Welsh, L., Cao, Y., Saksela, O., Kalkkinen, N. and Alitalo, K. (1997) Proteolytic processing regulates receptor specificity and activity of VEGF-C. EMBO J. 16, 3898-3911.

Kahari, V. M. and Saarialho-Kere, U. (1999) Matrix metalloproteinases and their inhibitors in tumor growth and invasion. Ann. Med. 31, 34-45.

Kanayama, H., Yokota, K., Kurokawa, Y., Murakami, Y., Nishitani, M. and Kagawa, S. (1998) Prognostic values of matrix metalloproteinase-2 and tissue inhibitor of metalloproteinase-2 expression in bladder cancer. Cancer 82, 1359-1366

Kataoka, H., Uchino, H., Iwamura, T., Seiki, M., Nabeshima, K. and Koono, M. (1999) Enhanced tumor growth and invasiveness in vivo by a carboxyl-terminal fragment of alpha1proteinase inhibitor generated by matrix metalloproteinases: a possible modulatory role in natural killer cytotoxicity. Am. $J$. Pathol. 154, 457-468.

Kim, D. and Chung, J. (2002) Akt: versatile mediator of cell survival and beyond. J. Biochem. Mol. Biol. 35, 106-115.

Kim, Y. M., Jang, J. W., Lee, O. H., Yeon, J., Choi, E. Y., Kim, K. W., Lee, S. T. and Kwon, Y. G. (2000) Endostatin inhibits endothelial and tumor cellular invasion by blocking the activation and catalytic activity of matrix metalloproteinase. Cancer Res. 60, 5410-5413

Konstantopoulos, K. and McIntire, L. V. (1997) Effects of fluid dynamic forces on vascular cell adhesion. J. Clin. Invest. 100, S19-S23.

Koshikawa, N., Giannelli, G., Cirulli, V., Miyazaki, K. and Quaranta, V. (2000) Role of cell surface metalloprotease MT1MMP in epithelial cell migration over laminin-5. J. Cell. Biol. 148, 615-624.

Kuo, C. J., LaMontagne, K. R. Jr., Garcia-Cardena, G., Ackley, B. D., Kalman, D., Park, S., Christofferson, R., Kamihara, J., Ding, Y. H., Lo, K. M., Gillies, S., Folkman, J., Mulligan, R. C. and Javaherian, K. (2001) Oligomerization-dependent regulation of motility and morphogenesis by the collagen XVIII NC1/endostatin domain. J. Cell. Biol. 152, 1233-1246.

Kurahara, S., Shinohara, M., Ikebe, T., Nakamura, S., Beppu, M., Hiraki, A., Takeuchi, H. and Shirasuna, K.(1999) Expression of MMPS, MT-MMP, and TIMPs in squamous cell carcinoma of the oral cavity: correlations with tumor invasion and metastasis. Head Neck 21, 627-638.

Lee, A. Y., Akers, K. T., Collier, M., Li, L., Eisen, A. Z. and Seltzer, J. L. (1997) Intracellular activation of gelatinase A (72kDa type IV collagenase) by normal fibroblasts. Proc. Natl. Acad. Sci. USA 94, 4424-4429.

Levi, E., Fridman, R., Miao, H. Q., Ma, Y. S., Yayon, A. and Vlodavsky, I. (1996) Matrix metalloproteinase 2 releases active 
soluble ectodomain of fibroblast growth factor receptor 1. Proc. Natl. Acad. Sci. USA 93, 7069-7074.

Liabakk, N. B., Talbot, I., Smith, R. A., Wilkinson, K. and Balkwill, F. (1996) Matrix metalloprotease 2 (MMP-2) and matrix metalloprotease 9 (MMP-9) type IV collagenases in colorectal cancer. Cancer Res. 56, 190-196.

Lijnen, H. R., Ugwu, F., Bini, A. and Collen, D. (1998) Generation of an angiostatin-like fragment from plasminogen by stromelysin-1 (MMP-3). Biochemistry 37, 4699-4702.

Lochter, A., Galosy, S., Muschler, J., Freedman, N., Werb, Z. and Bissell, M. J. (1997) Matrix metalloproteinase stromelysin-1 triggers a cascade of molecular alterations that leads to stable epithelial-to-mesenchymal conversion and a premalignant phenotype in mammary epithelial cells. J. Cell. Biol. 139, 1861-1872.

Malik, A. B. (1983) Pulmonary microembolism. Physiol. Rev. 63, 1114-1207.

Maquoi, E., Frankenne, F., Noel, A., Krell, H. W., Grams, F. and Foidart, J. M. (2000) Type IV collagen induces matrix metalloproteinase 2 activation in HT1080 fibrosarcoma cells. Exp. Cell Res. 261, 348-359.

Martin, D. C., Ruther, U., Sanchez-Sweatman, O. H., Orr, F. W. and Khokha, R. (1996) Inhibition of SV40 T antigen-induced hepatocellular carcinoma in TIMP-1 transgenic mice. Oncogene 13, 569-576.

Masson, R., Lefebvre, O., Noel, A., Fahime, M. E., Chenard, M. P., Wendling, C., Kebers, F., LeMeur, M., Dierich, A., Foidart, J. M., Basset, P. and Rio, M. C. (1998) In vivo evidence that the stromelysin-3 metalloproteinase contributes in a paracrine manner to epithelial cell malignancy. J. Cell. Biol. 140, 15351541.

McCawley, L. J. and Matrisian, L. M. (2001) Matrix metalloproteinases: they're not just for matrix anymore! Curr. Opin. Cell Biol. 13, 534-540.

McQuibban, G. A., Gong, J. H., Tam, E. M., McCulloch, C. A., Clark-Lewis, I. and Overall, C. M. (2000) Inflammation dampened by gelatinase A cleavage of monocyte chemoattractant protein-3. Science 289, 1202-1206.

Mehta, P. (1984) Potential role of platelets in the pathogenesis of tumor metastasis. Blood 63, 55-63.

Morris, R., Winyard, P. G., Blake, D. R. and Morris, C. J. (1994) Thrombin in inflammation and healing: relevance to rheumatoid arthritis. Ann. Rheum. Dis. 53, 72-79.

Mott, J. D., Thomas, C. L., Rosenbach, M. T., Takahara, K., Greenspan, D. S. and Banda, M. J. (2000) Post-translational proteolytic processing of procollagen C-terminal proteinase enhancer releases a metalloproteinase inhibitor. J. Biol. Chem. 275, 1384-1390.

Murphy, G. and Gavrilovic, J. (1999) Proteolysis and cell migration: creating a path? Curr. Opin. Cell Biol. 11, 614-621.

Nash, G. F., Turner, L. F., Scully, M. F. and Kakkar, A. K. (2002) Platelets and cancer. Lancet Oncol. 3, 425-430.

Nguyen, M., Arkell, J. and Jackson, C. J. (2001) Human endothelial gelatinases and angiogenesis. Int. J. Biochem. Cell Biol. 33, 960-970.

Nieswandt, B., Hafner, M., Echtenacher, B. and Mannel, D. N. (1999) Lysis of tumor cells by natural killer cells in mice is impeded by platelets. Cancer Res. 59, 1295-1300.

Noe, V., Fingleton, B., Jacobs, K., Crawford, H. C., Vermeulen, S., Steelant, W., Bruyneel, E., Matrisian, L. M. and Mareel, M.
(2001) Release of an invasion promoter E-cadherin fragment by matrilysin and stromelysin-1. J. Cell Sci. 114, 111-118.

Oh, J., Takahashi, R., Kondo, S., Mizoguchi, A., Adachi, E., Sasahara, R. M., Nishimura, S., Imamura, Y., Kitayama, H., Alexander, D. B., Ide, C., Horan, T. P., Arakawa, T., Yoshida, H., Nishikawa, S., Itoh, Y., Seiki, M., Itohara, S., Takahashi, C. and Noda M. (2001) The membrane-anchored MMP inhibitor RECK is a key regulator of extracellular matrix integrity and angiogenesis. Cell 107, 789-800.

Ohashi, K., Nemoto, T., Nakamura, K. and Nemori, R. (2000) Increased expression of matrix metalloproteinase 7 and 9 and membrane type 1-matrix metalloproteinase in esophageal squamous cell carcinomas. Cancer 88, 2201-2209.

Patterson, B. C. and Sang, Q. A. (1997) Angiostatin-converting enzyme activities of human matrilysin (MMP-7) and gelatinase B/type IV collagenase (MMP-9). J. Biol. Chem. 272, 2882328825.

Pei, D. and Weiss, S. J. (1995) Furin-dependent intracellular activation of the human stromelysin-3 zymogen. Nature 375, 244-247.

Pepper, M. S. (2001) Role of the matrix metalloproteinase and plasminogen activator-plasmin systems in angiogenesis. Arterioscler. Thromb. Vasc. Biol. 21, 1104-1117.

Philippe, C., Philippe, B., Fouqueray, B., Perez, J., Lebret, M. and Baud, L. (1993) Protection from tumor necrosis factor-mediated cytolysis by platelets. Am. J. Pathol. 143, 1713-1723.

Pozzi, A., Moberg, P. E., Miles, L. A., Wagner, S., Soloway, P. and Gardner, H. A. (2000) Elevated matrix metalloprotease and angiostatin levels in integrin alpha 1 knockout mice cause reduced tumor vascularization. Proc. Natl. Acad. Sci. USA 97, 2202-2207.

Rhee, J. S. and Coussens, L. M. (2002) RECKing MMP function: implications for cancer development. Trends Cell Biol. 12, 209211.

Riedel, F., Gotte, K., Schwalb, J., Bergler, W. and Hormann, K. (2000) Expression of 92-kDa type IV collagenase correlates with angiogenic markers and poor survival in head and neck squamous cell carcinoma. Int. J. Oncol. 17, 1099-1105.

Sato, H., Takino, T., Okada, Y., Cao, J., Shinagawa, A., Yamamoto, E. and Seiki, M. (1994) A matrix metalloproteinase expressed on the surface of invasive tumor cells. Nature 370, 61-65.

Sawicki, G., Salas, E., Murat, J., Miszta-Lane, H. and Radomski, M. W. (1997) Release of gelatinase A during platelet activation mediates aggregation. Nature 386, 616-619.

Shalinsky, D. R., Brekken, J., Zou, H., McDermott, C. D., Forsyth, P., Edwards, D., Margosiak, S., Bender, S., Truitt, G., Wood, A., Varki, N. M. and Appelt, K. (1999) Broad antitumor and antiangiogenic activities of AG3340, a potent and selective MMP inhibitor undergoing advanced oncology clinical trials. Ann. N. Y. Acad. Sci. 878, 236-270.

Sheu, B. C., Hsu, S. M., Ho, H. N., Lien, H. C., Huang, S. C. and Lin, R. H. (2001) A novel role of metalloproteinase in cancer-mediated immunosuppression. Cancer Res. 61, 237-242.

Silvestre, J. S., Mallat, Z., Tamarat, R., Duriez, M., Tedgui, A. and Levy, B. I. (2001) Regulation of matrix metalloproteinase activity in ischemic tissue by interleukin-10: role in ischemiainduced angiogenesis. Circ. Res. 89, 259-264.

Sternlicht, M. D. and Werb, Z. (2001) How matrix metalloproteinases regulate cell behavior. Annu. Rev. Cell Dev. 
Biol. 17, 463-516.

Sun, J. and Hemler, M. E. (2001) Regulation of MMP-1 and MMP-2 production through CD147/extracellular matrix metalloproteinase inducer interactions. Cancer Res. 61, 22762281.

Takahashi, C., Sheng, Z., Horan, T. P., Kitayama, H., Maki, M., Hitomi, K., Kitaura, Y., Takai, S., Sasahara, R. M., Horimoto, A., Ikawa, Y., Ratzkin, B. J., Arakawa, T. and Noda, M. (1998) Regulation of matrix metalloproteinase-9 and inhibition of tumor invasion by the membrane-anchored glycoprotein RECK. Proc. Natl. Acad. Sci. USA 95, 13221-13226.

Vince, G. H., Wagner, S., Pietsch, T., Klein, R., Goldbrunner, R. H., Roosen, K. and Tonn, J. C. (1999) Heterogeneous regional expression patterns of matrix metalloproteinases in human malignant gliomas. Int. J. Dev. Neurosci. 17, 437-445.

von Bredow, D. C., Nagle, R. B., Bowden, G. T. and Cress, A. E. (1997) Cleavage of beta 4 integrin by matrilysin. Exp. Cell Res. 236, 341-345.

Westermark, J. and Kahari, V. M. (1999) Regulation of matrix metalloproteinase expression in tumor invasion. FASEB J. 13, 781-792.

Westermarck, J., Li, S., Jaakkola, P., Kallunki, T., Grenman, R. and Kahari, V. M. (2000) Activation of fibroblast collagenase-1 expression by tumor cells of squamous cell carcinomas is mediated by p38 mitogen-activated protein kinase and c-Jun NH2-terminal kinase-2. Cancer Res. 60, 7156-7162.

Wojtukiewicz, M. Z., Tang, D. G., Ciarelli, J. J., Nelson, K. K., Walz, D. A., Diglio, C. A., Mammen, E. F. and Honn, K. V. (1993) Thrombin increases the metastatic potential of tumor cells. Int. J. Cancer 54, 793-806.

Yoon, S. O., Kim, M. M. and Chung, A. S. (2001) Inhibitory effect of selenite on invasion of HT1080 tumor cells. J. Biol. Chem. 276, 20085-20092.

Yoon, S. O., Park, S. J., Yoon, S. Y., Yun, C. H. and Chung, A. S. (2002) Sustained production of $\mathrm{H}_{2} \mathrm{O}_{2}$ activates pro-matrix metalloproteinase-2 through receptor tyrosine kinases/ phosphatidylinositol 3-kinase/NF-kappa B pathway. J. Biol. Chem. 277, 30271-30282.

Yu, Q. and Stamenkovic, I. (2000) Cell surface-localized matrix metalloproteinase-9 proteolytically activates TGF-beta and promotes tumor invasion and angiogenesis. Genes Dev. 14, 163-716.

Zhou, Z., Apte, S. S., Soininen, R., Cao, R., Baaklini, G. Y., Rauser, R. W., Wang, J., Cao, Y. and Tryggvason, K. (2000) Impaired endochondral ossification and angiogenesis in mice deficient in membrane-type matrix metalloproteinase I. Proc. Natl. Acad. Sci. USA 97, 4052-4057. 